\title{
Minorias, direitos de crianças e adolescentes: notas sobre o reconhecimento, proteção e promoção nas perspectivas do direito da sexualidade e do direito da antidiscriminação
}

\author{
Minorities, rights of children and adolescents: notes on \\ recognition, protection and promotion in the perspectives \\ of sexual rights and anti-discrimination Law
}

\section{Roger Raupp Rios}

\section{Resumo}

A compreensão dos direitos sexuais de crianças e de adolescentes deve atentar, simultaneamente, para a proteção diante da violência sexual, bem como para o reconhecimento de direitos e de medidas antidiscriminatórias que possibilitem seu desenvolvimento saudável, informado pelos direitos humanos e fundamentais da liberdade, da igualdade e do respeito à dignidade humana. Desse modo, evitam-se os riscos de que tal necessária e imprescindível proteção possa resultar, ainda que bem intencionada, em simultânea negativa de direitos e prejuízo para crianças e adolescentes.

Palavras-chave: Direito da Antidiscriminação. Direitos Sexuais. Infância. Adolescência.

\begin{abstract}
The legal comprehension of children's and adolescents' sexual rights must pay attention to protection against sexual offenses, as well as to anti-discrimination measures in order to guarantee their healthy developement, according to the principles of liberty, equality, and human dignity. In doing so, it is possible to avoid the risks involved in protection initiatives which can harm them and result in the denial of their rights.
\end{abstract}

Keywords: Anti-Discrimination Law. Sexual Rights. Childhood. Teenagerhood. 


\section{Introdução}

Esta reflexão trata do tema dos direitos sexuais de crianças e de adolescentes, a partir das vertentes do direito da sexualidade e do direito da antidiscriminação. A mera enunciação deste debate, para alguns, é evitada. Tal circunstância caracteriza estes grupos, do ponto de vista da proteção de seus direitos, como uma minoria. Minoria, aqui entendida, num sentido amplo, "como grupos de cultura não-dominante dentro da sociedade em que inseridos e que, por isso, são suscetíveis de maior violação de seus direitos" (Bragato, 2013).

Em geral a temática dos direitos sexuais, ainda mais aliada à perspectiva da antidiscriminação, é motivo de pânico moral e intelectual, quando se trata de analisar os direitos de crianças e de adolescentes. Todavia, é preciso avançar e colocar este debate de modo objetivo e racional, ciente de que é insuficiente uma abordagem meramente repressiva e centrada na preocupação que se restrinja somente aos necessários e urgentes objetivos que são prevenir o abuso, a violência e a exploração. Sobre estes, não há dúvida para afirmar seu caráter hediondo e sua inaceitabilidade, sob quaisquer circunstâncias. No entanto, é preciso ir além, e discutirem-se os direitos de crianças e adolescentes, diante da sexualidade, tendo presente uma abordagem positiva, educadora e integradora da sexualidade, tanto na experiência individual, quanto coletiva.

Com efeito, os danos causados a todos indivíduos, em especial a estes grupos, pelo silenciamento e a discriminação quanto ao exercício da sexualidade, são evidentes e graves, e não podem ser ocultados, nem perpetuados, pela dificuldade ante o tema.

É preciso, pois, levar a sério a titularidade dos direitos à liberdade sexual, à proibição de discriminação por orientação sexual, ao respeito à identidade de gênero, à dignidade como autonomia para desenvolver projetos de vida (o que inclui trajetórias diversas da heterossexualidade compulsória).

Neste contexto, explicitam-se não somente o caráter cultural, histórico e mutante de cada fase de vida e de sua caracterização na vida em sociedade, como também a pluralidade de vivências e experiências sexuais, em especial na adolescência. Tudo desafiando o pensar e o praticar o direito vigente, indo além de um paradigma meramente negativo, que concebe proteção somente como restrição e censura.

Para tanto, serão desenvolvidas algumas notas, a partir do direito da sexualidade e do direito da antidiscriminação, trazendo para o debate sobre os direitos de crianças e de adolescentes contribuições destas duas áreas.

Como dito, neste debate prevalece a resposta pela proteção de crianças e adolescentes diante de situaçōes de abuso, violência e exploração sexuais, ficando em segundo plano, quando não enfraquecidos ou até mesmo desprezados, a titularidade e o exercício de direitos sexuais por tais sujeitos, sejam considerados como indivíduos ou como grupos.

De fato, não obstante a enunciação de direitos humanos e fundamentais pela legislação nacional e internacional em favor de crianças e de adolescentes, acompanhada da qualificação destes como sujeitos de direitos (em contraposição à história de redução destes a objetos de regulação e controle por parte de adultos e de instituiçōes), a interpretação e a ênfase que se tem dado na elaboração destes instrumentos legislativos é outra.

O tratamento jurídico das diversas dimensōes da vida de crianças e de adolescentes, de modo geral, e de modo particular, na esfera da sexualidade, articula-se em torno da ideia de proteção ante a possibilidade e a realidade de violaçōes de direitos, sem, todavia, elaborar-se uma perspectiva promotora de direitos e, portanto, apta a colaborar com o desenvolvimento individual e social destes sujeitos de direitos.

Este fenômeno decorre, no caso dos direitos sexuais, não somente pela persistência de visões negativas e repressoras da sexualidade em geral, como também, particularmente, por uma dificuldade ainda maior diante da sexualidade na experiência de crianças e de adolescentes. 
Deste modo, apresenta-se a tensão, no debate sobre os direitos sexuais das crianças e de adolescentes, entre os princípios de proteção e de autonomia. De um lado, diante das dificuldades de lidar com a sexualidade de modo amplo, e de modo peculiar, com a sexualidade na vida de crianças e adolescentes, enfatiza-se que a proteção diante das violaçōes sexuais é o que realmente importa. De outro lado, invoca-se a necessidade de levar a sério a titularidade de direitos por parte destes sujeitos de direitos humanos $e$ fundamentais, inclusive na esfera da sexualidade, apontando-se que a autonomia pressuposta para o exercício dos direitos efetivamente vai se construindo passo a passo, o que abre caminho para o reconhecimento e o exercício destes direitos.

A presente reflexão adiciona duas ordens de consideração a este debate. Trata-se de aportar as perspectivas do direito da antidiscriminação e do direito da sexualidade diante da atenção à proteção diante da violações sexuais e ao exercício dos direitos sexuais por crianças e adolescentes. Objetiva-se, assim, explicitar e salientar alguns conteúdos já presentes neste campo, bem como acrescentar outros pontos de vista, conduzindo a uma postura que, sem descuidar a proteção diante da violência sexual, valorize os direitos sexuais de crianças e de adolescentes e colabore para a realização destes direitos. Neste percurso, ganha-se, inclusive, maior clareza, possibilitando escapar de certas armadilhas, situaçōes e dinâmicas onde a desejada proteção pode resultar, sem qualquer intenção, em simultânea negativa de direitos e prejuízo para crianças e adolescentes.

\section{0 aporte do direito da sexualidade ao debate sobre direitos de crianças $e$ adolescentes}

Como referi alhures (Rios, 2007), o direito da sexualidade é um campo da reflexão e da siste- matização do conhecimento jurídico, que se propōe a lançar bases para uma discussão jurídica mais abrangente e coerente dos direitos sexuais, a partir da enunciação de princípios jurídicos fornecidos pelos direitos humanos aplicáveis às questōes trazidas pelos direitos sexuais. Neste contexto, a sexualidade e os direitos sexuais que a ela se associam não são abordados como objetos carentes de disciplina ética ou de intervenção terapêutica, para as quais o ordenamento jurídico seria um dos instrumentos privilegiados de formulação e de legitimação, ao lado de áreas de conhecimento tais como a medicina, a psicanálise ou o pensamento religioso. Nem abordados como elementos cujo significado só teria sentido acaso atrelados à família, às relaçōes de parentesco, à constituição da subjetividade individual ou da realidade social (Loyola, 1999). Diversamente, sexualidade e direitos sexuais são abordados como elementos cujo influxo dos princípios fundamentais fornecidos pelos direitos humanos pode e deve pautar, em uma sociedade democrática, os olhares das diversas ciências e saberes que deles se ocupam.

Com efeito, desenvolver a idéia de direitos sexuais na perspectiva dos direitos humanos aponta para a possibilidade do livre exercício responsável da sexualidade, criando as bases para uma regulação jurídica que supere as tradicionais abordagens repressivas que caracterizam as intervençōes jurídicas nestes domínios. Implica, por assim dizer, uma compreensão positiva dos direitos sexuais, na qual o conjunto de normas jurídicas e sua aplicação possam ir além de regulaçōes restritivas, forjando condiçōes para um direito da sexualidade que seja emancipatório em seu espírito.

Para tanto, é preciso buscar princípios capazes de abarcar, simultaneamente, os grandes eixos ${ }^{1}$ que têm estruturado o debate corrente sobre os direitos sexuais, a saber, as questōes identitárias

\footnotetext{
${ }^{1}$ Estes eixos foram listados por Sérgio Carrara, em palestra no seminário Homossexualidades: identidade, política e produçāo cultural, realizado pela ABIA - Associação Brasileira Interdisciplinar de AIDS, no Rio de Janeiro, em 29 de outubro de 2002.
} 
vinculadas à expressão da sexualidade (onde se inserem, principalmente, os temas das homossexualidades), as relações sexuais propriamente ditas e suas consequências (campo que alcança matérias diversas como consentimento, violência e aborto) e a busca da fundamentação dos direitos sexuais (historicamente atada à idéia de saúde sexual).

A construção desta abordagem exige que se considere a relação entre democracia, cidadania, direitos humanos e direitos sexuais, bases a partir das quais será proposto um modelo de compreensão democrático dos direitos sexuais, que denomino direito democrático da sexualidade.

No esforço ora desenvolvido, destacarei algumas notas, relativas ao objeto de proteção, à titularidade e às funçōes desempenhadas pelos direitos sexuais, tendo presente o debate sobre direitos sexuais de crianças e adolescentes.

\section{a. 0 objeto de proteção dos direitos sexuais e os direitos de crianças e de adolescentes}

As realidades da vida individual e social relacionadas à sexualidade são múltiplas. Alcançam esferas individual e coletiva, aspectos da vida pública e privada, ao mesmo tempo que são articuladas e tem repercussões insitucionais, políticas e sociais.

De fato, a sexualidade vai muito além da vivência do erotismo e do prazer experimentadas a partir do corpo biológico, muito mais do que um fenômeno da natureza. Ela abarca prazeres, desejos, experiências, identidades, orientaçōes, que são construídas e ganham significado social, cultural e político; ela cria identidades e articula classificaçōes a partir destas identidades, institui distinçōes e diferenciaçōes, repercutindo na atribuição de direitos, deveres, limites, restrições e sujeiçōes. A sexualidade, em suma, na expressão consagrada de Michel Foucault, é um dispositivo de poder.

Ela atinge a vida privada e pauta a atuação do estado, pela legislação, jurisprudência e políticas públicas. Revela-se um dos eixos pelos quais a vida individual, coletiva, social, política e cultural se organiza, como pode-se perceber na moda, na etiqueta, na construção dos gêneros, na arquitetura.

Nada disso é natural ou neutro. Predomina uma determinada visão de mundo, que pode ser qualificada, para os fins desta reflexão, como uma ordem adultocêntrica e heterossexista.

Imprescindível, portanto, desenvolver uma perspectiva ampla da sexualidade, à qual corresponde um direito da sexualidade, sistematizando princípios e investigando seus conteúdos e consequências, inclusive diante do debate sobre os direitos de crianças e de adolescentes.

Neste quadro, temos, de um lado, uma ordem adultocêntrica e heterossexista, e, de outro, uma concepção política, jurídica e ética que busca, no referencial dos direitos humanos, dos direitos fundamentais e mesmo do Estatuto da Criança e do Adolescente, organizar a vida em sociedade de acordo com conteúdos de direitos humanos e fundamentais, onde as criancas $e$ adolescentes sejam efetivamente tratadas como sujeitos de direito.

No campo dos direitos sexuais em geral, esta perspectiva ampla reclama ainda muito trabalho. A história dos direitos sexuais, no cenário internacional, se os compreendermos como âmbito do conhecimento e da prática jurídica, mostra isso: eles são reduzidos e limitados, na maior parte das vezes, a legítimas e necessárias preocupações com a saúde reprodutiva e desigualdade de gênero. Além destas fronteiras (e mesmo dentro delas, como demonstra o debate acerca da autonomia reprodutiva feminina), os direitos sexuais efetivamente carecem de aceitação e estão muito distantes de consenso. Ao contrário, até são formalmente rejeitados.

Neste contexto, não é de se espantar que, no caso das crianças e adolescentes, predominem abordagens protetivas exclusivamente preocupadas com a violência e distantes do desenvolvimento, 
gozo e exercício da sexualidade, nas suas mais variadas expressōes.

Como referido acima, isto é fruto, pelo menos, em virtude da ausência de uma abordagem positiva da sexualidade e pelo acento quase exclusivo na prevenção de danos. Para avançar, é preciso atentar para o objeto de proteção do direito da sexualidade e relacioná-lo com o debate ora proposto. A atenção sobre a titularidade dos direitos e as funçōes dos direitos sexuais, defensivas e promotoras, oportuniza este movimento.

\section{b. A titularidade dos direitos sexuais por crianças e adolescentes}

Os direitos básicos da pessoa humana, veiculados no direito internacional dos direitos humanos e no catálogo de direitos fundamentais constitucionalmente previsto, são de titularidade universal. Seu objeto são os bens da vida mais necessários e essenciais para o desenvolvimento das capacidades humanas. Este dado normativo é ilustrado sem deixar dúvidas quando se trata de liberdade, autonomia, dignidade, e não-discriminação, sem distinção de cor, raça, sexo e idade.

Apesar da aparente obviedade desta afirmação, sabe-se que não é truísmo insistir que determinados indivíduos e grupos são titulares destes direitos. Por muito tempo, e ainda hoje, a titularidade de vários direitos é disputada, por exemplo, quando se trata de mulheres ou homossexuais. A situação aqui discutida, envolvendo crianças e adolescentes, também requer atenção.

Como dito, muitas vezes certos direitos fundamentais, e, em especial, sua concretização no âmbito da sexualidade, são restringidos ao máximo, quando não, na prática, intencionalmente omitidos ou inconscientemente desapercebidos, em especial diante de crianças e adolescentes. A liberdade sexual e a não-discriminação por orientação sexual e por identidade de gênero são situaçōes particularmente aflitivas para crianças e adolescentes, em cuja presença a rejeição da titularidade destes direitos é recorrente.

\section{c. As funções defensivas e promotoras dos direitos sexuais de crianças e adolescentes}

Os direitos humanos em geral, e os direitos sexuais do mesmo modo, desempenham funçōes de defesa contra violaçōes de bens jurídicos fundamentais, bem como de promoção destes bens.

Considere-se a tríade dos direitos de liberdade, de igualdade e de respeito à dignidade da pessoa humana. Estes podem visualizados, do ponto de vista histórico e do filosófico, como centrais dentre todos os demais direitos catalogados como humanos ou fundamentais. Em sua primeira geraçāo, identificados como negativos, veiculando defesa contra intromissōes abusivas, registram liberdades individuais cuja dimensão alcança diversas esferas constitutivas da sexualidade (Rios, 2011).

No caso de crianças e de adolescentes, eles significam muito diante de uma ordem adultocêntrica e heterossexista. Defesa diante de intromissōes arbitrárias sempre que se queira instrumentalizar o desenvolvimento pessoal de alguém que, devidamente informado, livre de constrangimentos e de forma espontânea, oriente suas experiências e se experimente e construa como homossexual ou transgênero, ou simplesmente desenvolva uma identidade de gênero heterossexual não conforme àquilo que hegemonicamente se considere como própria e adequadamente heterossexual.

Deste modo, confluem os direitos de liberdade, de igualdade e de dignidade da pessoa humana (Rios, 2011). Dignidade humana entendida como espaço autônomo de experimentação, amadurecimento e construção de seu destino, de acordo com suas preferências, desejos e tendências, sem ser tomado como objeto de um projeto heterônomo, onde uma pessoa é vista como alguém a encarnar uma determinada concepção heterossexista de individuo, de família, de sociedade e ate mesmo de Estado. Para tanto, é necessário respeitar a liberdade individual que, sem dúvida, crianças e adolescentes aos poucos e, efetivamente, vão construindo e experimentando em suas trajetórias, livres de discriminação. 
Deste modo, perceber que direitos sexuais têm como objeto de proteção a sexualidade, e dar-se conta de como a sexualidade é muito mais do que uma confirmação de tal ou qual pedagogia de práticas ou identidades conforme esta ou aquela visão de mundo, faz concluir que liberdade, igualdade e respeito à dignidade, compreendidos no quadro do direito da sexualidade, dizem respeito aos direitos sexuais de crianças e de adolescentes, num contexto maior que a proteção contra violência, abuso e exploração sexual. Dito de outro modo, pode-se traduzir a preocupação com evitar a violência sexual como significa afastar a violência do heterossexismo que, excluído desta dimensão de defesa, viola a liberdade, a igualdade e a dignidade de crianças e adolescentes, ao interferir arbitrariamente no desenvolvimento dos projetos de vida, que vão se construindo aos poucos e continuamente, ao longo de suas vidas. Evidentemente, tal proceder, violador de direitos, pela imposição do heterosssexismo, compromete a universalidade da titularidade destes direitos, deles excluindo crianças e adolescentes.

Um direito da sexualidade, na esteira do debate contemporâneo sobre as dimensōes dos direitos humanos, avança para a consideração dos direitos sociais e econômicos, tidos como segunda geração de direitos humanos e qualificados na doutrina constitucional como direitos positivos, direitos a prestaçōes, vocacionados para a promoção da liberdade e da igualdade fáticas.

Nesta linha, uma variada gama de prestaçōes tem sido arrolada nos instrumentos internacionais de proteção de direitos humanos, tais como: (1) acesso a informaçōes e educação sexual e reprodutiva; (2) serviços de saúde sexual e de saúde reprodutiva, acessíveis, seguros e adequados a toda população, incluindo o acesso ao progresso científico através da oferta de tratamentos e medicamentos, que garantam o controle por homens e mulheres de sua fecundidade; (3) serviços social e legal de suporte para o exercício desses direitos; (4) políticas de segurança para coibir e eliminar todo o tipo de violência, especialmente na escola, e em todos os âmbitos de atuação das politicas publicas; (5) políticas que promovam e garantam a igualdade e eqüidade entre os sexos, não permitindo a submissão das mulheres e meninas, eliminando toda e qualquer discriminação sexual; (6) políticas que promovam e estabeleçam a responsabilidade pessoal e social dos homens em relação ao seu comportamento sexual e fertilidade, e pelo bem-estar de suas companheiras e filhas (Ventura, 2003: 51).

Direitos sociais de cunho prestacional, assim, mostram-se aptos a abarcar uma série de situaçōes pertinentes ao exercício da sexualidade, cujas repercussōes pode-se aquilatar claramente para crianças e adolescentes.

De fato, liberdade e proteção contra discriminação requerem condiçōes materiais para se realizarem. Ao pensar-se na situação de seres humanos nas fases da vida da infância e da adolescência, é injusto ignorar estes direitos, considerando: (1) a necessidade de receber informaçōes, adequadas ao discernimento, mas efetivamente recebê-las, sobre saúde, reprodução, diversidade sexual, tudo livre de preconceito e além de um projeto de amoldamento das crianças e dos adolescentes ao projeto heterossexista; (2) o direito de conviver em ambientes onde a diversidade sexual e a própria sexualidade sejam apresentados de modo nao preconceituoso, tendencioso ou parcial; (3) ter acesso a proteção jurídica, biomédica e psicológica diante de violaçōes de direitos, inclusive quando estas violaçōes ocorrem no interior da família, perpetradas por pais ou responsáveis.

Exemplo disso, no cenário nacional recente, foi a polêmica gerada pelo chamado kit anti-homofobia, a ser utilizado nas escolas públicas. Crianças e adolescentes têm o direito positivo de medidas, no ambiente escolar, que não só as protejam de violência, como também informem sobre a diversidade sexual, ampliando sua liberdade sexual e respeitando o direito de igualdade, tudo em favor do respeito a sua dignidade humana. 


\section{0 aporte do direito da antidiscriminação ao debate sobre os direitos sexuais de crianças e de adolescentes}

Assim como o direito da sexualidade objetiva organizar, sistematizar e dar coerência às normas jurídicas incidentes sobre as as relaçōes sociais pertinentes à esfera da sexualidade, o direito da antidiscriminação tem propósito idêntico, agora diante do fenômeno discriminatório. Cuida-se de um ramo do conhecimento e da prática jurídica que, partindo do conceito jurídico de discriminação (que desfruta, no direito brasileiro, inclusive, de hierarquia constitucional2², estuda os conceitos, institutos, princípios e respostas jurídicas antidiscriminatórias (Rios, 2008).

Nos tópicos seguintes, serão relacionados dois elementos cruciais do direito da antidiscriminação ao debate sobre os direitos sexuais de crianças e adolescentes: o conceito de discriminação e algumas manifestaçōes discriminatórias juridicamente inadmissíveis, decorrentes da desconsideração de direitos sexuais de crianças e adolescentes.

\section{a) o conceito de discriminação e os direitos de crianças e adolescentes}

Juridicamente falando, discriminação é toda distinção, exclusão, restrição ou preferência, que tenha o propósito ou o efeito de anular, restringir ou prejudicar o reconhecimento, o gozo e o exercício, em pé de igualdade, de direitos humanos, em virtude de sexo, raça, origem, etnia e idade, nos diversos campos da vida econômica, política, social e cultural. Não bastasse a proibição explícita, constitucionalmente prevista, de discriminação contra crianças e adolescentes (artigo 227), a inclusão expressa, na lista de critérios proibidos de discriminação do fator idade, revela a proteção constitucional antidiscriminatória em favor destes grupos.
Trata-se de uma compreensão do conteúdo jurídico da igualdade como mandamento antidiscriminatório, que visa a combater situaçōes injustas de subordinação, que criem uma cidadania de segunda classe. No caso dos direitos sexuais de crianças e adolescentes, como referido desde a introdução, muitas vezes acaba prevalecendo uma atitude protecionista, negativa diante da sexualidade, que, do modo como engendrada, que leva ao enfraquecimento, quando não à negação, de tais direitos.

Este resultado, proposital ou não, configura discriminação, na medida em que restringe, anula e mesmo não reconhece direitos como a autonomia, o respeito à dignidade e a não-discriminação a crianças e adolescentes. Acaba-se por prejudicar, restringir e até mesmo anular direitos em função do critério etário. Tudo num ambiente onde predomina uma cosmovisão adultocêntrica, subordinadora de crianças e dos adolescentes aos adultos, sob o pretexto de protegê-los.

Crianças, desde a primeira infância, e adolescentes, durante todo seu desenvolvimento, são socializados em ambientes onde as representaçōes, os discursos, os espaços arquitetônicos, as possibilidades de convívio, são informadas de modo determinado, qual seja, o heterossexismo (entendido como ideologia que hierarquiza as expressōes, manifestaçōes, práticas e identidades sexuais, valorando positivamente a heterossexualidade, qualificando-o como normal e saudável, ao passo que a homossexualidade e outras expressōes divorciadas na norma heterossexual são tachadas de anormais e desviantes, quando não abjetas). ${ }^{3}$

Esta experiência, distante dos paradigmas da diversidade sexual e do respeito às diferenças, produz consequências danosas para a inserção, formação e desenvolvimento pessoal e comunitário de crianças e adolescentes. Ao invés disso,

\footnotetext{
${ }^{2}$ O conceito jurídico de discriminação, previsto na Convenção Internacional sobre os Direitos das Pessoas com Deficiência, foi incorporado no direito nacional com força de emenda constitucional, uma vez que observado o disposto no parágrafo 3 do artigo 5 da Constituição de 1988.

${ }^{3}$ Ver Louro, 2010.
} 
uma sociedade plural e democrática, onde estes direitos sejam levados a sério, de uma maneira positiva, abre-lhes o espaço para Ihes possibilitar mais saúde e felicidade, longe da repressão e da violência heterossexistas.

\section{b) o silenciamento e a injúria como rejeição da diversidade: práticas discriminatórias diante do direitos sexuais de crianças e adolescentes}

Neste quadro heterossexista, violaçōes de direitos, configuradoras de discriminação, não somente são frequentes, como também se perpetuam e renovam. Desde as mais violentas e intensas atitudes homofóbicas (de que são exemplos agressões físicas e morais contra crianças e adolescentes homossexuais e transgêneros, que alcançam o extremo do homicídio), até a discriminação difusa e silenciosa, praticada no seio das instituições de educação, de saúde e nos meios de comunicação, a tudo isto crianças e adolescentes são constantemente expostas, em virtude do desrespeito a seus direitos sexuais.

Uma das manifestações mais danosas é a injúria homofóbica. Ela é manifestação de violência não-física, que, nas palavras de José Reinaldo de Lima Lopes (2005), "é a negativa de valor a uma forma de ser ou de viver, e é ela que está por trás das formas de tratamento degradante $e$ insultuoso a certas pessoas e grupos, pois promove o desrespeito por formas individuais ou coletivas de viver." Esta injúria é assim descrita por Didier Eribon, lembrado por Lima Lopes (2005):

O que a injúria me diz é que sou alguém anormal ou inferior, alguém sobre quem o outro tem poder e, antes de tudo, o poder de me ofender. A injúria é, pois, o meio pelo qual se exprime a assimetria entre os indivíduos. [...] Ela tem igualmente a força de um poder constituinte. Porque a personalidade, a identidade pessoal, a consciência mais íntima, é fabricada pela existência mesma dessa hierarquia e pelo lugar que ocupamos nela e, pois, pelo olhar do outro, do "dominante", e a faculdade que ele tem de inferiorizar-me insultando-me, fazendo- me saber que ele pode me insultar, que sou uma pessoa insultável e insultável ao infinito (p. 57).

A injúria homofóbica inscreve-se em um contínuo que vai desde a palavra dita na rua que cada gay ou lésbica pode ouvir (veado sem- vergonha, sapata sem-vergonha) até as palavras que estão implicitamente escritas na porta de entrada da sala de casamentos da prefeitura: "proibida a entrada de homossexuais" e, portanto, até as práticas profissionais dos juristas que inscrevem essa proibição no direito, e até os discursos de todos aqueles $e$ aquelas que justificam essas discriminaçōes nos artigos que se apresentam como elaboraçōes intelectuais (filosóficas, sociológicas, antropológicas, psicanalíticas etc.) e que não passam de discursos pseudocientíficos destinados a perpetuar a ordem desigual, a reinstituí-la, seja invocando a natureza ou a cultura, a lei divina ou as leis de uma ordem simbólica imemorial. Todos esses discursos são atos, e atos de violência (p. 62).

Estas manifestaçōes no cotidiano de crianças e de adolescentes, ora promovidas, ora assentidas, por indivíduos e por instituiçōes, violam direta e gravemente direitos sexuais, na contramão dos deveres de promoção, de criação de condições que lhes deem chances de desenvolver seus projetos de vida. Sem isso, não se levam a sério os direitos fundamentais de crianças e adolescentes, fazendo-Ihes objeto do heterossexismo; pior ainda, propalando-se a proteção de crianças e adolescentes quando, em verdade, elas são usadas como pretexto para se impor a heteronormatividade (isto é, observância compulsória dos padrōes e condutas preconizados pelo heterossexismo).

\section{Conclusão}

Direitos sexuais de crianças e adolescentes apresentam-se num cenário tormentoso e desafiador. Seja pela intensidade da violência e da exploração sexuais desferida contra muitos, seja pela dificuldade em abordar positivamente a esfera da sexualidade e sua importância fundamental para um desenvolvimento sadio e equilibrado. 
Ciente deste desafio, aumentam as tarefas do direito da sexualidade e do direito da antidiscriminação, sem os quais não serão levados a sério os mais básicos direitos sexuais de crianças e de adolescentes. Os riscos de uma perspectiva dominada por um protecionismo negativo e restritivo são ainda maiores numa sociedade heterossexista, na medida que os direitos humanos e sexuais destes grupos são ofuscados, quando não anulados, pela heteronormatividade.

Neste contexto, as normas protetivas e promotoras dos direitos de crianças e adolescentes tem sua concretização cada vez mais exigida, a fim de que Ihes seja emprestado conteúdo positivo, capaz de integrar a sexualidade conforme os ditames do convívio democrático. Esta tarefa é tão urgente e necessária quanto a denúncia e o combate à exploração sexual destes grupos, sob pena de o enfrentamento à violação de direitos básicos de crianças e adolescentes ficar incompleto e comprometido.

\section{Referências bibliográficas}

BRAGATO, F. F. "Reflexōes sobre a formação das minorias: uma análise sobre a racionalidade moderna, os direitos humanos e a não-discriminação", capítulo desta obra coletiva.
LOURO, G. 2010."Sexualidades minoritárias e educação: novas políticas?"In: Políticas de enfrentamento ao heterossexismo: corpo e prazer. Porto Alegre: Nuances (p. 143-150).

LOPES, J. R. L. 2005. O direito ao reconhecimento para gays e lésbicas. Sur, Rev. int. direitos human. [online], vol.2, n.2 [cited 2013-04-02], pp. 64-95. Available from: http://www.scielo.br/scielo.php?script=sci arttext\&pid=S1806-4452005000100004\&lng=en\&n rm=isos. ISSN 1806-6445. http://dx.doi.org/10.1590/ S1806-64452005000100004.

LOYOLA, M. A. 1999. A sexualidade como objeto de estudo das ciências humanas. In: HEILBORN, Maria Luiza (Org.). Sexualidade : o olhar das ciências sociais. Rio de Janeiro: Jorge Zahar.

RIOS, R. R. 2007. Direito da Antidiscriminação. Porto Alegre: Livraria do Advogado, 2008.

. "Notas para o desenvolvimento de um direito democrático da sexualidade". In Em Defesa dos Direitos Sexuais. (org. Roger Raupp Rios). Porto Alegre: Livraria do Advogado, (p. 13-38).

"Direitos sexuais, uniōes homossexuais e a decisão do Supremo Tribunal Federal (ADPF no 132 e ADI 4.277)". In Homossexualidade e Direitos Sexuais: reflexōes a partir da decisão do do STF (org. Roger R. Rios, Célio Golin e Paulo G. C. Leivas). Porto Alegre: Sulina, 2011.

VENTURA, M. (Org.) 2003. Direitos sexuais e direitos reprodutivos na perspectiva dos direitos humanos. Rio de Janeiro: Advocaci.

\section{Roger Raupp Rios}

Mestre e Doutor em Direito (Universidade Federal do Rio Grande do Sul - Brasil). Professor do PPG - Mestrado em Direitos Humanos da UniRitter. Juiz Federal em Porto Alegre (roger.raupp.rios@gmail.com). 